\title{
Autosomal recessive forms of hereditary motor and sensory neuropathy
}

\author{
A E HARDING AND P K THOMAS \\ From the Department of Neurological Science, Royal Free Hospital, London
}

SUMMARY Six families are described with hereditary motor and sensory neuropathy (HMSN) of probable autosomal recessive inheritance. Four of these were classified as HMSN type I and two as type II. The consanguinity rate in this series was high, suggesting that these recessive genes are rare. In comparison with the dominantly inherited forms of these disorders, the mean age of onset was significantly earlier for the type II cases but did not differ for the type I patients. Motor nerve conduction velocity was significantly less for the type I cases but did not differ for the type II form. The recessive type I cases tended to show a greater incidence of weakness, ataxia, tendon areflexia and scoliosis than in the dominant form. The importance of differentiating such cases from Friedreich's ataxia is emphasised.

Several studies in recent years have established that peroneal muscular atrophy (Charcot-Marie-Tooth disease) is genetically complex. Cases formerly given this designation can be separated into hereditary distal spinal muscular atrophy and hereditary motor and sensory neuropathy (HMSN). Furthermore, cases of HMSN are divisible, on clinical and electrophysiological grounds, into types I and II. ${ }^{1-5}$ Patients with type I HMSN usually have an early age of onset (mostly in the first decade), distal muscle weakness in all four limbs, and a high incidence of tendon areflexia, distal sensory loss and foot deformity. Motor conduction velocity in the median nerve is almost always less than $38 \mathrm{~m} \mathrm{~s}^{-1}$. Patients with type II HMSN are generally less severely affected; in particular, weakness in the hands is less common and there is a lower incidence of spinal and foot deformity. The tendon reflexes and sensation are better preserved. The age of onset of symptoms is most frequently in the second decade, but a considerable proportion develop symptoms later. Motor conduction velocity in the median nerve is almost always greater than $38 \mathrm{~m} \mathrm{~s}^{-1}$ and may be normal, but sensory conduction is always abnormal. ${ }^{5}$ Pathologically, both disorders are associated with axonal loss in the peripheral nerves. In type I HMSN, this is associated with extensive segmental

Address for reprint requests: Professor PK Thomas, Department of Neurological Science, Royal Free Hospital, Pond Street, London NW3 2QG.

Accepted 31 January 1980 demyelination and remyelination, and sometimes with hypertrophic changes; demyelination is sparse in type II HMSN.

Since the original description of peroneal muscular atrophy by Charcot and $\mathrm{Marie}^{6}$ and Tooth, ${ }^{7}$ it has been noted that the majority of cases are dominantly inherited. A smaller number of cases exhibiting autosomal recessive inheritance have been reported. Bell $^{8}$ collected 34 such families from the literature. Many of the early descriptions are complicated by the confusing classifications that arose following the description of two siblings with hypertrophic neuropathy by Dejerine and Sottas. ${ }^{9}$ A number of the cases reported as Dejerine-Sottas disease in the literature could be labelled as autosomal recessive Charcot-Marie-Tooth disease and vice versa. Furthermore, the term Dejerine-Sottas disease has been widely used to describe any patient with hypertrophic neuropathy, regardless of inheritance or aetiology. Hypertrophic neuropathy is now known to be nonspecific and to be caused by a wide range of inherited and acquired demyelinating neuropathies including type I HMSN, Refsum's disease and chronic relapsing or chronic progressive idiopathic inflammatory polyneuropathy. ${ }^{10}$

Dyck and Lambert ${ }^{1}$ proposed that the term 'Dejerine-Sottas disease' should be reserved for patients with an onset of severe, progressive, disabling neuropathy in infancy. In Dyck and Lambert's cases, motor development was much delayed and at best subnormal. The prognosis was worse than in type I HMSN and the cases were of 
autosomal recessive inheritance or had no family history. Motor nerve conduction velocity was usually less than $10 \mathrm{~m} \mathrm{~s}^{-1}$. The cerebrospinal fluid protein level was increased. Dyck et al. ${ }^{11}$ showed that the pathological changes in the peripheral nerves included hypomyelination as well as recurrent demyelination, and Dyck et al. ${ }^{12}$ reported an as yet unconfirmed disturbance of ceramide hexoside metabolism. Dyck ${ }^{13}$ suggested that these patients should be classified as HMSN type III.

The original family described by Dejerine and Sottas does not accord with these proposed diagnostic criteria for HMSN type III, as one of their cases did not develop symptoms until aged 14 years. It would be most satisfactory, therefore, to abandon the eponymous title of Dejerine-Sottas disease and to reserve the category of HMSN type III for patients with a severe, progressive, infantile neuropathy with hypomyelination and very low nerve conduction velocities. This classification thus includes the cases of congenital hypomyelination such as described by Lyon ${ }^{14}$ and Kennedy and co-workers. ${ }^{15}$ This group of patients is probably genetically heterogeneous.

Despite the fact that a number of families with autosomal recessively inherited HMSN have been reported, there have been no detailed descriptions of such families since the introduction of the classification of these disorders discussed above. Moreover, to date there have been no well documented descriptions of the autosomal recessive form of HMSN type II. This paper describes the clinical features of six families with the autosomal recessive form of HMSN, four of which were classified as type I and two as type II. It should be stressed that none of these patients is an example of type III HMSN.

The index cases of these families were seen during a prospective study on the nosology of peroneal muscular atrophy. Methods of ascertainment, classification and an overall description of the clinical features for a total of 227 patients have been described elsewhere. ${ }^{516}$ In addition to the cases reported in this communication, there are 26 single cases of type I and 16 type II HMSN which had no family history of similar disorder. In two cases the parents were cousins. Segregation analysis suggests that the disease was recessively inherited in about $70 \%$ of the single generation type I cases but only in about $25 \%$ in type II. ${ }^{16}$ As these cases cannot be identified, the present report is confined to patients with affected siblings.

\section{Case reports}

Family 1 (pedigree in fig 1 )

II 3 This 5 year old Jordanian girl was noted to be
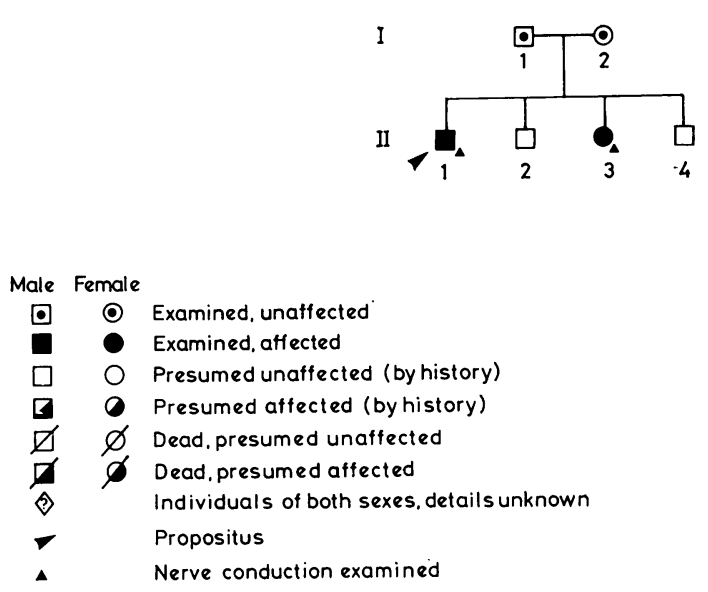

Fig 1 Pedigree of Family 1.

hypotonic at the age of one year and did not walk until she was $2 \frac{1}{2}$ years old. She was observed to have difficulty using her hands.

On examination she had generalised wasting and hypotonia in the legs and weakness in all four limbs. There was generalised tendon areflexia. Adequate sensory testing was not possible. She had a thoracic scoliosis. The peripheral nerves were not thickened.

Electromyography (EMG) of the left deltoid and abductor digiti minimi revealed spontaneous fibrillation and a reduced motor unit recruitment pattern. The right extensor digitorum brevis was completely denervated. Median motor nerve conduction velocity (MNCV) was $10 \mathrm{~m} \mathrm{~s}^{-1}$. No index finger/wrist median sensory action potential (SAP) was detected. The CSF protein was $0 \cdot 3 \mathrm{~g}^{-1}$.

The child was reviewed in Beirut two years later by $\operatorname{Dr}$ A K Afifi. She was unable to walk without support but her disability had not obviously progressed significantly. A sural nerve biopsy at that stage showed a moderately severe depletion of myelinated nerve fibres. Some of the remaining fibres, in the process of remyelination, had inappropriately thin myelin sheaths for the axon diameter; others had sheaths of normal thickness. There was extensive concentric Schwann cell proliferation with multiple small onion bulbs. A few regenerative clusters were present (figs 2 and 3).

II 1 , brother of II 3 . At the age of 13 years this boy was noted to have highly arched feet and to walk on the lateral borders of his feet.

On examination there was mild distal wasting and weakness of the small hand muscles. He had slight ataxia on finger-nose testing. There was distal wasting in the lower limbs with moderate weakness of dorsiflexion and eversion at the ankles and 


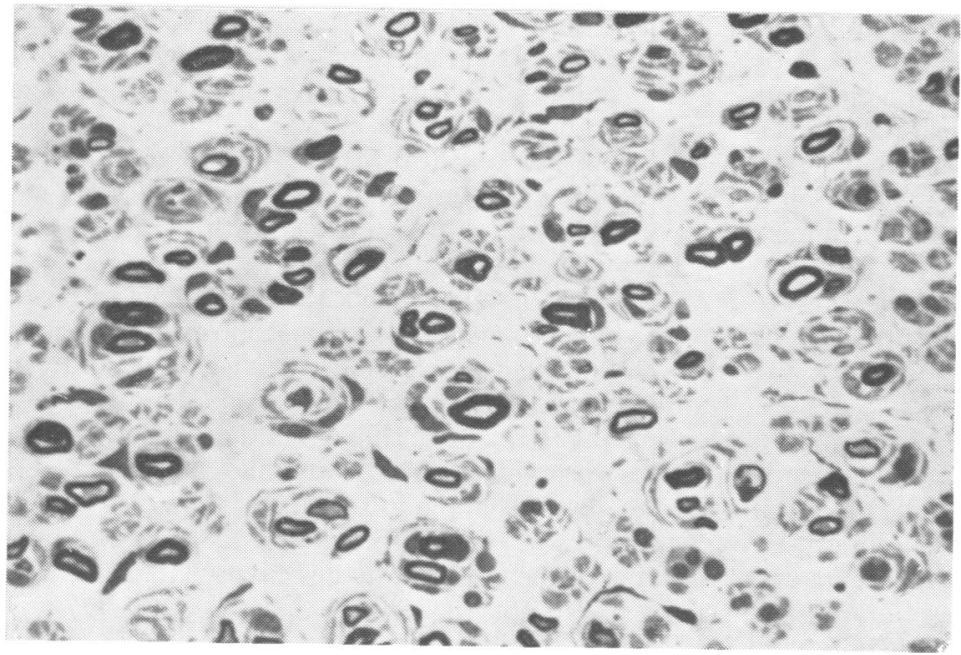

Fig 2 Portion of transverse section from sural nerve biopsy in Case II.3, Family 1, showing depleted population of myelinated fibres. Some of the remaining fibres have myelin sheaths of normal thickness; in others the thickness is reduced relative to axon size indicating remyelination. Concentric Schwann cell proliferation is seen in several places, giving rise to small 'onion bulbs'. Thionin and acridine orange stain, Epon embedding; $\times 425$.

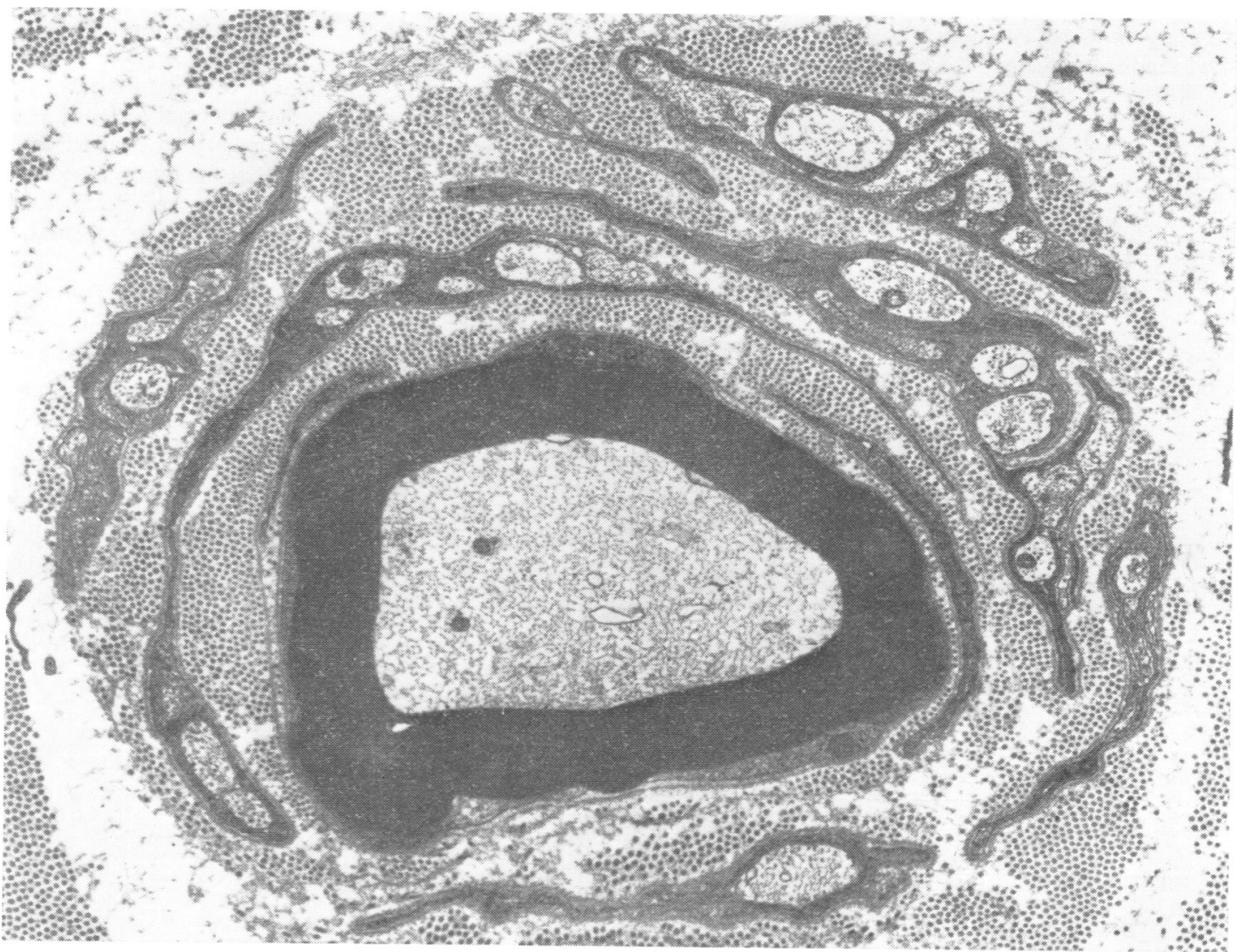

Fig 3 Electron micrograph of transverse section through myelinated nerve fibre from sural nerve biopsy in Case II.3, Family I. The fibre is surrounded by a concentric array of Schwann cell processes and associated unmvelinated axons, together with collagen fibrils. $\times 10,000$. (Figure kindly provided by $\operatorname{Dr}$ AK Afifi). 
extension of the toes. The tendon reflexes were all absent. He had bilateral pes cavus with clawing of the toes. Vibration sense was lost on the toes but there was no other sensory loss. Both radial nerves were thickened at the wrists.

MNCV was $17 \mathrm{~m} \mathrm{~s}^{-1}$ in the median nerve and $11 \mathrm{~m} \mathrm{~s}^{-1}$ in the peroneal. No median SAP (finger/ wrist) was detectable.

The parents (I 1 and I 2) of these patients were unrelated and asymptomatic. No abnormality was found on clinical examination.

\section{Family 2 ( fig 4)}

III 4 This 14 year old boy was noted to be unsteady from the age of 15 months and a diagnosis of Friedreich's ataxia was made in early childhood. He developed a scoliosis at the age of seven years and had had abnormally shaped feet since infancy.

On examination he had distal wasting and weakness in the upper limbs with ataxia on fingernose testing. There was severe weakness in all muscle groups below the knees and heel-shin ataxia. The tendon reflexes were all absent and joint

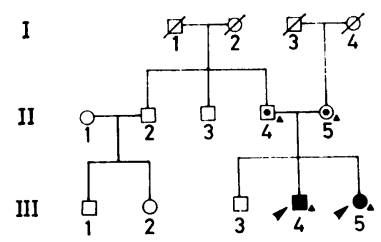

Fig 4 Pedigree of Family 2. position sense and light touch appreciation were impaired distally in all four limbs. He had scoliosis and bilateral pes cavus. The peripheral nerves were not thickened.

Median and peroneal MNCV was 18 and $12 \mathrm{~m} \mathrm{~s}^{-1}$ respectively. The median SAP (finger-wrist) was reduced in amplitude $(1 \mu \mathrm{V})$, with a prolonged latency to peak $(4.5 \mathrm{~ms})$.

III 5 , sister of III 4, aged 15 years. This girl was noted by her parents to have a scoliosis at the age of 14 years. She was stated to be "gawky" and her athletic performance was poor. She had no weakness or wasting in the upper limbs but definite finger-nose ataxia was evident. There was mild distal weakness in the legs. The tendon reflexes were all absent. Sensation was normal. She had a scoliosis and mild clawing of the toes, but no pes cavus. The peripheral nerves were not thickened.

Median MNCV was $29 \mathrm{~m} \mathrm{~s}^{-1}$. The median SAP was of small amplitude $(3.5 \mu \mathrm{V})$ with a prolonged latency to peak $(5 \cdot 8 \mathrm{~ms})$.

The parents (II 4 and 5) were unrelated and clinically normal. Peroneal MNCV in the mother was $57 \mathrm{~m} \mathrm{~s}^{-1}$ and conduction velocity in the sural nerve $44 \mathrm{~m} \mathrm{~s}^{-1}$ with an action potential amplitude of $18 \mu \mathrm{V}$. The corresponding values for the father were $50 \mathrm{~m} \mathrm{~s}^{-1}$ for both nerves with an action potential amplitude of $23 \mu \mathrm{V}$ in the sural nerve. Their eldest son (III 3) aged 19 years was stated to be normal.

\section{Family 3 ( fig 5)}

III 12 This 19 year old boy presented in early adolescence with unsteadiness on walking and a

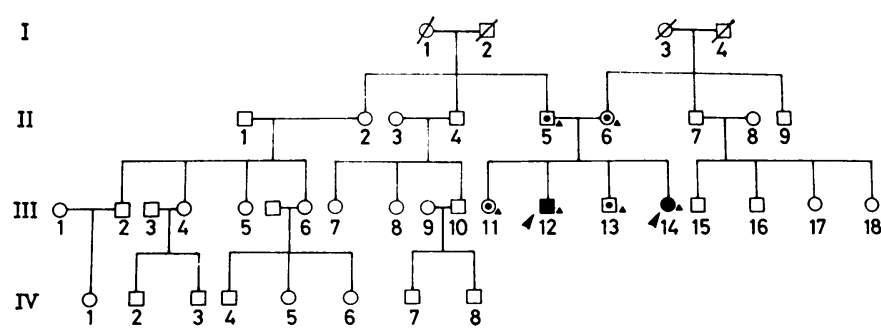

Fig 5 Pedigree of Family 3.

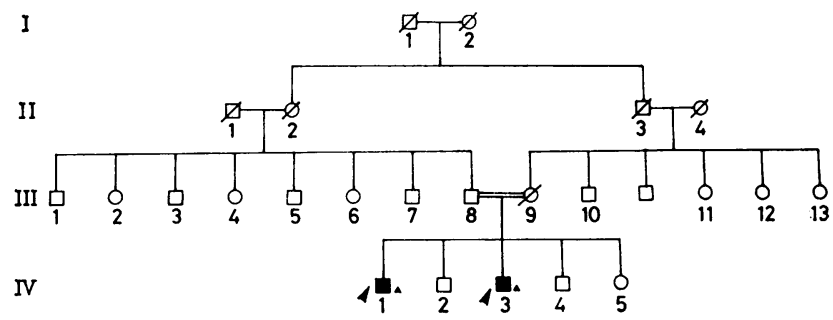

Fig 6 Pedigree of Family 4. 
tendency to trip.

On examination he had mild wasting and weakness of the small hand muscles with clawed fingers and ataxia on finger-nose testing. The legs were wasted below the knees and distally weak with heel-shin ataxia. He had bilateral pes cavus and a kyphoscoliosis. All his tendon reflexes were absent. Joint position sense was defective in the fingers and toes and vibration sense was lost in the feet. The peripheral nerves were thickened.

Median MNCV was $19 \mathrm{~m} \mathrm{~s}^{-1}$. The extensor digitorum brevis was totally denervated bilaterally. No median SAP was detectable.

III 14 , sister of 111 12, aged 15 years, had noticed poor balance and a tendency for her ankles to 'give way' for five years.

On examination she had mild ataxia of the upper limbs but no weakness. There was distal wasting and weakness in the legs and mild ataxia. All the tendon reflexes were absent and all sensory modalities were reduced below the knees. Her peripheral nerves were not thickened.

Median MNCV was $19 \mathrm{~m} \mathrm{~s}^{-1}$. The extensor digitorum brevis was totally denervated bilaterally and no median SAP was detectable.

Both of these patients' parents (II 5 and 6) and siblings (III 11 and 13) were clinically normal. Median and peroneal MNCV and median sensory action potential amplitudes and latencies to peak were as follows: II $5: 52 \mathrm{~m} \mathrm{~s}^{-1}, 42 \mathrm{~m} \mathrm{~s}^{-1}, 12 \mu \mathrm{V}$, $3.3 \mathrm{~ms}$; II 6: $63 \mathrm{~m} \mathrm{~s}^{-1}, 49 \mathrm{~m} \mathrm{~s}^{-1}, 10 \mu \mathrm{V}, 3.2 \mathrm{~ms}$; III 11: $57 \mathrm{~m} \mathrm{~s}^{-1}, 44 \mathrm{~m} \mathrm{~s}^{-1}, 14 \mu \mathrm{V}, 2 \cdot 7 \mathrm{~ms}$; III 13: $62 \mathrm{~m} \mathrm{~s}^{-1}, 41 \mathrm{~m} \mathrm{~s}^{-1}, 20 \mu \mathrm{V}, 3 \mathrm{~ms}$. Common peroneal mixed nerve action potentials in III 11 and 13 had amplitudes of 7 and $9 \mu \mathrm{V}$ respectively with inflection velocities of 47 and $47 \mathrm{~m} \mathrm{~s}^{-1}$.

Family 4 ( fig 6)

IV I This 35 year old Iranian man had noticed slight weakness of his legs for 20 years and similar symptoms in the hands for 15 years.

On examination there was moderate weakness and wasting of the small hand muscles; the anterior tibial muscles were wasted and he had weakness of dorsiflexion and eversion at the ankles and for flexion and extension of the toes. All his tendon reflexes were absent. There was loss of superficial sensation in a glove and stocking distribution and vibration sense was reduced in the feet. His peripheral nerves were not thickened.

Median MNCV was $13 \mathrm{~m} \mathrm{~s}^{-1}$ and no median SAP was detectable. The extensor digitorum brevis was totally denervated bilaterally.

IV 3, brother of IV 1 , aged 29 years. He had had difficulty in walking since the age of 13 years and more recent weakness of the hands. Surgical correction of foot deformity 10 years prior to examination had led to some improvement.

On examination he had severe weakness and wasting in the hands. The legs were wasted and weak below the knees. He showed bilateral clawing of the toes, pes cavus and shortening of the calf muscles. All the tendon reflexes were absent. Light touch and pain sensibility were severely reduced distally in the legs and less so in the hands. Vibration sense was lost in the feet. His peripheral nerves were not thickened.

EMG of the abductor digiti minimi showed changes of chronic partial denervation. Ulnar MNCV was $12 \mathrm{~m} \mathrm{~s}^{-1}$ and no median SAP was detectable. The extensor digitorum brevis was totally denervated bilaterally.

The boys' siblings were stated to be normal. Their mother was dead but had had no neurological disease; the father was well but unavailable for study. The parents were first cousins.

\section{Family 5 ( fig 7)}

IV 7 This 64 year old Englishman had difficulty in playing games at school at the age of 13 years; his

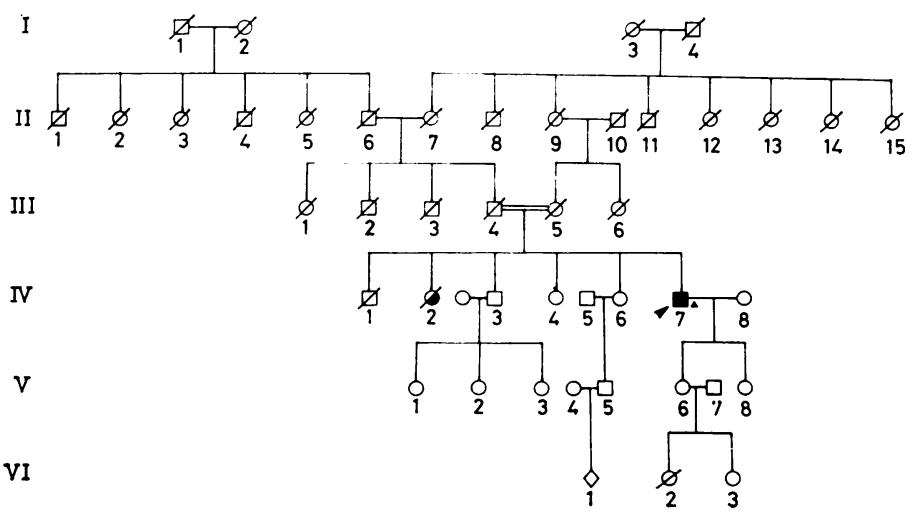

Fig 7 Pedigree of Family 5. 


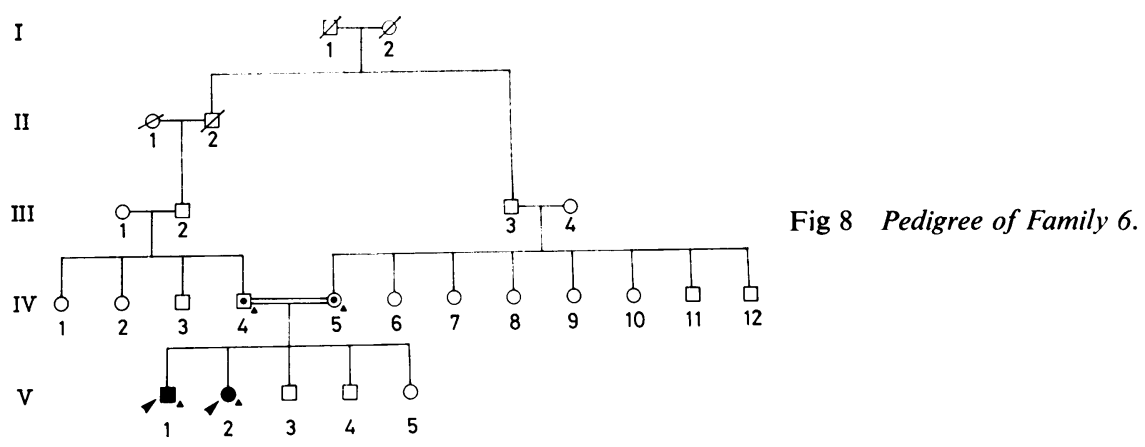

lower legs were always said to be thin. His military service was curtailed because of his disability. He denied any noticeable progression of the symptoms.

On examination he had bilateral mild sensorineural deafness and minimal dysarthria. The small hand muscles were wasted and weak. The legs were generally wasted with severe distal weakness. The ankle jerks were absent. Sensation was normal. $\mathrm{He}$ had mild pes cavus bilaterally. His peripheral nerves were not thickened.

EMG of the right abductor pollicis brevis and abductor digiti minimi showed a greatly reduced motor unit recruitment pattern on voluntary effort. Median MNCV was $55 \mathrm{~m} \mathrm{~s}^{-1}$. Ulnar and median SAPs were reduced in amplitude (5 and $6 \mu \mathrm{V})$, with latencies to peak of 3.5 and $4.0 \mathrm{~ms}$.

The patient's sister (IV 2) was stated to have 'weak ankles' and foot drop. His parents, who were first cousins, were stated to have been normal.

\section{Family 6 ( fig 8)}

$V 1$ This Turkish Cypriot boy, aged 15, first noticed unsteadiness on his feet at the age of 11 years. He tended to fall on running. His motor disability had progressively increased. He had had distal paraesthesiae in all four limbs for two years.

On examination there was severe wasting in the hands and forearms, and in the legs to mid-thigh level. Power was moderately reduced in the small hand muscles and severely for all muscle groups below the knees. He had a mild intention tremor in the upper limbs. The tendon reflexes were absent apart from the knee jerks. Cutaneous sensation was lost in a glove and stocking distribution and vibration and position sense were impaired in both feet. There was a mild scoliosis and bilateral pes planus. The peripheral nerves were not thickened.

EMG of the right extensor digitorum brevis showed a grossly reduced motor unit recruitment pattern; median MNCV was $53 \mathrm{~m} \mathrm{~s}^{-1}$; peroneal MNCV was $60 \mathrm{~m} \mathrm{~s}^{-1}$. No median SAP was detectable.
$V 2$, sister of $\mathrm{V} 1$ This 18 year old girl was never very athletic at school. Since the age of 12 she had noticed poor balance and difficulty in finding well-fitting shoes. She had recently developed clumsiness of the hands.

On examination she had bilateral wasting and weakness of the small hand muscles. There was moderate distal weakness in the lower limbs with shortening of the calf muscles and clawed toes but no pes cavus. She showed distal sensory impairment for all modalities in the legs with lesser changes in the hands. All her tendon reflexes were depressed and the ankle jerks were absent. Her peripheral nerves were not thickened.

EMG of the right extensor digitorum brevis showed spontaneous fibrillation and no motor unit activity. Median MNCV was $43 \mathrm{~m} \mathrm{~s}^{-1}$. No sural nerve action potential was detected.

Both parents, who were first cousins once removed, were examined and found to be clinically and electrophysiologically normal. Median and peroneal MNCV in the mother was 58 and $52 \mathrm{~m} \mathrm{~s}^{-1}$ respectively; the amplitude of the median SAP was $9 \mu \mathrm{V}$ with a latency to peak of $3.8 \mathrm{~ms}$. Her sural nerve action potential amplitude was $28 \mu \mathrm{V}$, latency $3.0 \mathrm{~ms}$, inflection velocity $45 \mathrm{~m} \mathrm{~s}^{-1}$. The father's median MNCV was $62 \mathrm{~m} \mathrm{~s}^{-1}$. His median SAP had an amplitude of $10 \mu \mathrm{V}$ and a latency to peak of $2.8 \mathrm{~ms}$; the amplitude of his sural nerve action potential was $42 \mu \mathrm{V}$, latency $2 \cdot 2 \mathrm{~ms}$ with an inflection velocity of $57 \mathrm{~m} \mathrm{~s}^{-1}$.

No phytanic acid was detected in the serum of any of these patients.

\section{Discussion}

The families described here demonstrate that there are autosomal recessive genes that give rise to both types of HMSN. All living parents of these patients except one were examined and found to be normal. One (Family 4, III 8), who lived in Rome, was 
inaccessible. In addition, six parents had nerve conduction studies performed with normal results. It is unlikely that any of the remainder had subclinical disease, as in the large series of patients with HMSN referred to in the Introduction ${ }^{5}$, no clinically normal individual had abnormal motor or sensory conduction. In some other series abnormalities of nerve conduction have been reported from clinically normal subjects. These were, however, individuals aged less than five years. ${ }^{1}$

The high incidence of consanguineous marriages in these families (three out of six, two being first cousins and one first cousins once removed), is additional evidence for autosomal recessive inheritance although two of them (families 4 and 6) are from communities where the incidence of cousin marriage is higher than in Britain (Cyprus and Jordan). Yet the rate of first cousin marriage is rarely higher than $30 \%{ }^{17}$ compared with $50 \%$ in this series, which includes one English family. Unfortunately it is not possible to use these values in order to calculate gene frequencies for these disorders as the families are from different populations. The high incidence of consanguinity would support the clinical impression that the recessive genes causing HMSN types I and II are rare, probably in the order of 1 in 50000 .

The clinical features of these cases are summarised in the table, with equivalent figures for autosomal dominant HMSN. ${ }^{5}$ It will be noted that the incidence of weakness, ataxia, total tendon areflexia and scoliosis is higher in the recessive cases. These differences are not statistically significant (using Yates' $\chi^{2}$ test) in the type I patients, but the numbers are small. Statistical analyses were not attempted in the type II group because of the even smaller numbers involved. Although the differences are not significant, it is interesting to note the relatively high incidence of scoliosis, ataxia and areflexia in the type I recessive cases. This is probably a major reason why patients of this type are misdiagnosed as having Friedreich's ataxia on clinical grounds, as occurred with III 4, family 2. This is not an uncommon diagnostic error and illustrates the importance of neurophysiological investigations in such patients as the prognosis for the two disorders is very different.

It is of interest that the mean median MNCV in the recessive cases of type I HMSN $\left(16.5 \mathrm{~m} \mathrm{~s}^{-1}\right)$ is significantly lower than that for the dominant group $\left(21 \cdot 1 \mathrm{~m} \mathrm{~s}^{-1}\right)$ (SND (standardized normal deviate) $=2.02, p<0.05$ ). It is not as low as Dyck and Lambert ${ }^{1}$ reported for cases of HMSN type III, where it was usually below $10 \mathrm{~m} \mathrm{~s}^{-1}$. In the type II recessive cases the mean median $\mathrm{MNCV}$ was not significantly different from that of dominant cases. Comparisons could not be made for the peroneal nerve because of the high proportion of recessive cases in which the extensor digitorum brevis was totally denervated.

It is a generally held view that recessive forms of a disorder are more severe than their dominant counterparts, if both genes exist. Severity in these patients is difficult to quantify, but can be assessed using a mean weakness score. ${ }^{5}$ In view of the small numbers of overtly recessive cases, mean weakness scores were not calculated for these groups. Certainly the general clinical impression is that the patients described here were more severely disabled than dominantly inherited cases. In a separate communication ${ }^{5}$ it was shown that the single generation cases of type I HMSN had higher mean weakness scores than the dominant form. The type II subgroups had similar scores. However, the mean age of onset, to some extent an objective measure of severity, for the type II recessive cases is considerably less than those with dominant inheritance (SND = $3.66, \mathrm{p}<0.001)$. The values for the type I cases are identical (recessive 9.9 years; dominant $9 \cdot 1$ years).

This latter point is of interest in terms of distinguishing autosomal recessive HMSN type $\mathbf{I}$ from type III or, if the term is to be retained, Dejerine Sottas disease. If the definition of HMSN type III

Table Clinical features of autosomal recessive HMSN compared with the dominant forms

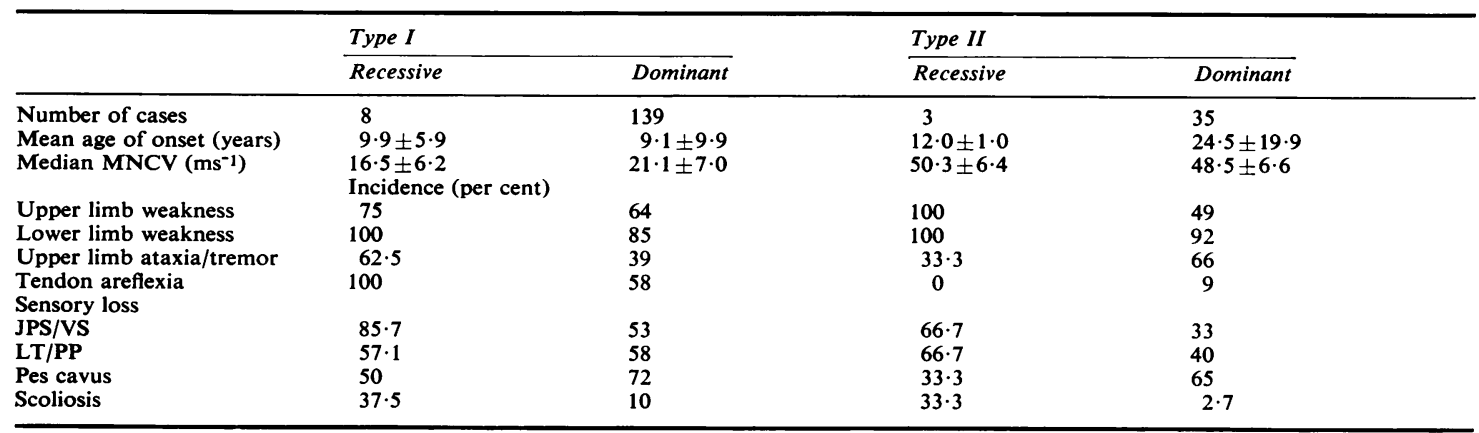


includes an onset in infancy, the only patient in the current series who could be classified as having this condition is II 3 , family 1 . However, the nerve biopsy findings were those of type I rather than type III HMSN. Moreover, her brother (II 1) did not develop symptoms until the age of 13 years. This family bears a remarkable similarity to that originally described by Dejerine and Sottas. ${ }^{9}$ Case III 4, family 2, also presented at the age of 15 months, whereas his sister was normal until the age of 13 years. Nevertheless, the clinical features in family 2 were not those of Dejerine-Sottas disease. There is obviously some overlap between the clinical features of cases of autosomal recessive HMSN type I and HMSN type III. This does not present much of a diagnostic problem where more than one sibling is affected, but it may do so in single cases. Delayed motor milestones are not confined to HMSN type III. The main distinguishing feature would appear to be the rate of progression of the disease. All of the patients in the present series were able to walk at the time of study. Dyck and colleagues ${ }^{11}$ have suggested that the disorders can be separated by morphometric study of nerve biopsies. This will reflect the nerve conduction changes.

To date there have been accounts of approximately $\mathbf{5 0}$ families with probable autosomal recessive HMSN in the literature, excluding those with additional features. ${ }^{18}$ 18-24 Unfortunately the parents of affected patients have rarely been examined clinically or electrophysiologically. As a moderate proportion $(16 \%)$ of patients with autosomal dominant HMSN are asymptomatic, ${ }^{5}$ it cannot be assumed that all the reported cases are of recessive inheritance. This is a particular problem in analysing Skre's cases. ${ }^{22}$ This author has described five families with probable autosomal recessive inheritance in western Norway. Despite meticulous examination of many family members, the issue is confused by the diagnosis of "unspecific neuropathy" in some relatives of the affected patients, including some of the parents of the cases assumed to be recessive. "Unspecific neuropathy" included the finding of "neuromuscular affection" and proprioceptive sensory loss. Nerve conduction studies were not performed. Physical signs may be minimal in autosomal dominant HMSN and therefore autosomal dominant inheritance cannot be excluded in some of Skre's families.

Beighton ${ }^{25}$ described an interesting Amish kinship which could be described as demonstrating "pseudodominant" inheritance. Although HMSN occurred in four generations with one example of parent-child transmission, the incidence of consanguinity in this kinship is so high (four cousin marriages) that the disorder could have been recessively inherited.
Some of the families in the literature have additional associated clinical features and so cannot be accepted as uncomplicated cases of HMSN. For example, Raymond (cited by Bell ${ }^{8}$ ) described three siblings with hypertrophic neuropathy and ichthyosis; these patients may well have had Refsum's disease. Câmpeanu and Morariu ${ }^{26}$ reported two families, one with acrodystrophy and mental retardation, the second having retinitis pigmentosa and mental retardation in addition to neuropathy. Several of the families cited by Bell ${ }^{8}$ had associated mental retardation and one had optic atrophy.

The majority of the autosomal recessive cases of HMSN described so far were reported before nerve conduction studies were available. These are therefore not divisible into types I and II. In recent years six families with probable autosomal recessive HMSN type I have been described ${ }^{1,23,24}$ but there are no convincing reports of autosomal recessive type II HMSN. Family 6 in this communication is a definite example of this syndrome and family 5 is highly likely to be recessive in view of the occurrence of consanguinity in this English kinship.

It is clear that the cases of autosomal recessive HMSN in the literature are a heterogeneous group. Nevertheless, the overall picture of these cases is that of a more severe disorder as compared with the dominantly inherited disease. This point was particularly made by Allan. ${ }^{19}$ Bell ${ }^{8}$ compared the mean age of onset between the recessive $(10.93 \pm 9.65$ years) and dominant (18.95 \pm 13.59 years) cases. The difference is highly significant $(\mathrm{t}=3 \cdot 12, \mathrm{p}<$ $0.001)$. This is difficult to correlate with the present series as there is no division of Bell's cases into types I and II; the differences in age of onset could well be due to a relatively low proportion of recessive: dominant cases of the type II form of HMSN, which has later age of onset than type $I$.

In comparing the severity of recessive and dominant HMSN, it is of interest to note that Killian and Kloepfer ${ }^{27}$ described two siblings who were probably homozygous for the dominant type I gene. Both parents and two children were clinically typical of autosomal dominant type I HMSN, but four of the offspring were severely affected, with an early age of onset, severe skeletal deformity and became chairbound by adolescence. One of these had three children all of whom had features of autosomal dominant HMSN. There was consanguinity in this family. The incidence of cousin marriage amongst parents of cases of autosomal recessive HMSN in the literature is not particularly high (about $15 \%$ ), considering that consanguinity was more common in the first quarter of this century when many of these families were described. Furthermore, most of the cousin mar- 
riages occurred in communities with a high consanguinity rate $\left(\operatorname{Iran}^{20}\right.$, western Norway ${ }^{22}$ and Amish ${ }^{25}$ ) considerably reducing their significance. The low consanguinity rate in cases of DejerineSottas disease in the literature made Pratt ${ }^{28}$ caution against accepting an autosomal recessive inheritance for this disorder.

The present series suggests that autosomal recessive HMSN is rare, particularly the type II form. A proportion of the families in the literature may be dominantly inherited with limited expression in the parents, or alternatively, different disorders altogether. It is important to distinguish cases of autosomal recessive HMSN types I and II from those of HMSN type III, as the prognosis is much worse in the latter. As patients with autosomal recessive HMSN types I and II may reproduce, the possibility of recessive inheritance should be considered in genetic counselling. Ideally, therefore, the parents of any patient with HMSN should be examined clinically and, wherever possible, nerve conduction studies performed.

We thank the Friedreich's Ataxia Group for financial assistance. We are also indebted to $\mathrm{Mr}$ HS Kemp, Mr CW Manning, Dr RS Kocen and Mr MH Yacoub for referring cases; to Dr AK Afifi for providing information about Case II 3, family 1 , and allowing us to examine the nerve biopsy specimen; to Mrs M Nourallah, Miss Jane Workman and Mr Paul Webster for technical assistance; and finally to Mrs K Price for help with translation.

\section{References}

1 Dyck PJ, Lambert EH, Lower motor and primary sensory neuron diseases with peroneal muscular atrophy. I Neurologic, genetic and electrophysiologic findings in hereditary polyneuropathy. Arch Neurol (Chic) 1968; 18:603-18.

2 Dyck PJ, Lambert EH. Lower motor and primary sensory neuron diseases with peroneal muscular atrophy. II. Neurologic, genetic and electrophysiologic findings in various neuronal degenerations. Arch Neurol (Chic) 1968; 18:619-25.

3 Thomas PK, Calne DB. Motor nerve conduction velocity in peroneal muscular atrophy: evidence for genetic heterogeneity. J Neurol Neurosurg Psychiatry 1974; 37:68-75.

4 Buchthal F, Behse F. Peroneal muscular atrophy and related disorders. I. Clinical manifestations as related with biopsy findings, nerve conduction and electromyography. Brain 1976; 99:41-66.

5 Harding AE, Thomas PK. The clinical features of hereditary motor and sensory neuropathy types I and II. Brain 1980; 80:259-80.

6 Charcot JM, Marie P. Sur une forme particulière d'atrophie musculaire progressive, souvent familiale, débutant par les pieds and les jambes et atteignant plus tard les mains. Rev Méd (Paris) 1886; 6:97-138.

7 Tooth HH. The peroneal type of progressive muscular atrophy. London: HK Lewis, 1886.

8 Bell J. On the peroneal type of progressive muscular atrophy. Treasury of Human Inheritance. Cambridge University Press, Vol. 4, Part VI, 1934.

9 Dejerine $\mathbf{H}$, Sottas J. Sur la névrite interstitielle, hypertrophique et progressive de l'enfance. $C R$ Soc Biol (Paris) 1893; 45:63-96.

10 Thomas PK, Lascelles RG, Stewart G. Hypertrophic neuropathy. In: Vinken PJ, Bruyn GW, eds Handbook of Clinical Neurology 1975; Vol. 21: 145-70.

11 Dyck PJ, Lambert EH, Sanders K, O'Brien PC. Severe hypomyelination and marked abnormality of conduction in Dejerine-Sottas hypertrophic neuropathy: myelin thickness and compound action potential of sural nerve in vitro. Mayo Clin Proc $1971 ; 46: 432-6$.

12 Dyck PJ, Ellefson RD, Lais AC, Smith RC, Taylor WF, Van Dyke RA. Histologic and lipid studies of sural nerve in inherited hypertrophic neuropathy: preliminary report of a lipid abnormality in nerve and liver in Dejerine-Sottas disease. Mayo Clin Proc 1970; 45:286-327.

13 Dyck PJ. Inherited neuronal degeneration and atrophy affecting peripheral motor, sensory and autonomic neurons. In: Dyck PJ, Thomas PK, Lambert EH eds Peripheral Neuropathy 1975; Philadelphia: Saunders, Vol. 2: 1975: 825-67.

14 Lyon G. Ultrastructure study of a nerve biopsy from a case of early infantile chronic neuropathy. Acta Neuropath 1969; 13:131-42.

15 Kennedy WR, Sung JH, Berry JF. A case of congenital hypomyelination neuropathy. Clinical, morphological and chemical studies. Arch Neurol (Chic) $1977 ; 34: 337-45$.

16 Harding AE, Thomas PK. Genetic aspects of hereditary motor and sensory neuropathy (Types I and II). J Med Genet 1980, in press.

17 Roberts JAF, Pembrey ME. An Introduction to Medical Genetics, 7th ed London; Oxford University Press; 1978: 17-18.

18 Davidenkow S. La forma recesiva de la amiotrofia Charcot-Marie. Rev Neurol (Buenos Aires) 1938; 3:177-84.

19 Allan W. Relation of hereditary pattern to clinical severity as illustrated by peroneal atrophy. Arch Int Med 1939; 63:1123-31.

20 Mahloudji M. A recessively inherited mixed polyneuropathy of early onset. J Med Genet 1969; 6:411-12.

21 Kalyanaraman K, Cancilla PA, Munsat T, Pearson CM. Hereditary hypertrophic neuropathy. Bull Los Angeles Neurol Soc 1970; 35: 58-68.

22 Skre H. Genetic and clinical aspects of CharcotMarie-Tooth disease. Clin Genet 1974; 6:98-118.

23 Brust JCM, Lovelace RE, Devi S. Clinical and electrodiagnostic features of Charcot-Marie-Tooth syndrome. Acta Neurol Scand 1978; 58: Supp 68, $1-142$.

24 Davis CJF, Bradley WG, Madrid R. The peroneal 
muscular atrophy syndrome. (Clinical, genetic, electrophysiological and nerve biopsy studies). J Génét Hum 1978; 26:311-49.

25 Beighton PH. Recessively inherited CharcotMarie-Tooth syndrome in identical twins. In: The Clinical Delineation of Birth Defects: Original Article Series 1971; 7:105.

26 Campeanu E, Morariu M. Les relations entre génotype et phénotype dans la maladie de CharcotMarie-Tooth, Rev roum Neurol 1970; 7:47-56.

27 Killian JM, Kloepfer HW. Homozygous expression of a dominant gene for Charcot-Marie-Tooth neuropathy. Ann Neurol 1979; 5:515-22.

28 Pratt RTC. In: The Genetics of Neurological Disorders; London; Oxford University Press, 1967: 86. 